\title{
A ORDEM ECONÔMICA E A REFORMA TRABALHISTA
}

\author{
Isabela Lins Martini ${ }^{99}$ \\ Natalia Biondi Gaggini Robles ${ }^{100}$
}

Recebido em: 30/04/2019

Aprovado em: 18/09/2019

\begin{abstract}
RESUMO
A ordem econômica constitucional brasileira é fundada na valorização do trabalho humano e na livre iniciativa, valores que podem colidir frequentemente num regime de mercado neoliberal. Com a promulgação da Reforma Trabalhista, muito se discute a respeito da desvalorização do trabalho humano, na precarização das condições de trabalho e na mitigação da dignidade da pessoa humana. Nesse sentido, pretende-se analisar os fundamentos, os princípios e os objetivos da ordem econômica a fim de entender se a Reforma Trabalhista de fato degradou as condições do trabalhador ou se tem o condão de reaquecer a economia e diminuir a taxa de desemprego.
\end{abstract}

Palavras-chave: Ordem Econômica. Economia. Reforma Trabalhista. Desemprego.

\section{INTRODUÇÃO}

A ordem constitucional econômica tem como fundamentos a valorização do trabalho humano e a livre iniciativa, fazendo-se presente nas disposições constitucionais que disciplinam o processo de interferência do Estado na condução da vida econômica (artigo 170 e seguintes, da Constituição da República Federativa do Brasil).

A ordem econômica é conjunto de normas que tem por finalidade prima a dignidade da pessoa humana e o zelo pela justiça social e pela garantia dos princípios constitucionais. Esta ordem está intrinsecamente ligada ao mercado de trabalho e, consequentemente, ao direito do trabalho.

Recentemente a legislação trabalhista sofreu grande e polêmica alteração, sendo alterados mais de 100 (cem) artigos da Consolidação das Leis do Trabalho.

\footnotetext{
99 Advogada e mestranda pela Pontifícia Universidade Católica de São Paulo em Relações Econômicas Internacionais.

${ }^{100}$ Advogada, especialista em Direito e Processo do Trabalho, especialista em Direito Público e mestranda pela Pontifícia Universidade Católica de São Paulo em Direito do Trabalho.
} 
O presente artigo tem por finalidade o estudo dos iniciais impactos econômicos da reforma trabalhista, mormente observando o contexto econômico do país quando da promulgação da Lei n. 13.467, de 13 de julho de 2017. Não há aqui a pretensão de esgotar o tema, principalmente diante do exíguo prazo transcorrido desde a promulgação e vigência da referida lei.

\section{ORDEM CONSTITUCIONAL ECONÔMICA}

Em apertada síntese, os princípios presentes na Constituição da República Federativa do Brasil (CRFB) são normas finalísticas. Assumem eles um status de norma jurídica, denotando positividade e vinculatividade e gerando eficácia positiva e negativa sobre comportamentos públicos ou privados e sobre a interpretação e a aplicação de outras normas. Uma vez presentes os princípios na CRFB, explícita ou implicitamente, eles se caracterizam como valores supremos e fundantes de todo o ordenamento jurídico, assim como determinam diretrizes e interpretações.

Os princípios estampados nos incisos do artigo 170, da CRFB, delimitam e definem os vetores e os valores supremos da ordem econômica, quais sejam a soberania nacional, a propriedade privada, a função social da propriedade, a livre concorrência, a defesa do consumidor, a defesa do meio ambiente, a redução das desigualdades regionais e sociais, a busca do pleno emprego e o tratamento favorecido para empresas brasileiras de pequeno porte.

Contudo, deve-se elevar como valores supremos a existência digna e a justiça social, ainda que sejam previstos como objetivos da ordem social. Do mesmo modo, os fundamentos da ordem econômica - a valorização do trabalho humano e a livre iniciativa - devem ser vistos como pilares antagônicos ${ }^{101}$ para todo o sistema de princípios previsto nos incisos do artigo 170 da CRFB. Isto é, de um lado existe o aspecto trabalhista, que não necessariamente se preocupa com objetivos sociais, e do outro lado existe o aspecto econômico, que se preocupa com as relações financeiras.

\footnotetext{
101 A expressão "antagônicos" foi utilizada como referência à valorização do trabalho humano e à livre iniciativa como forma de mostrar a dualidade que existe nos fundamentos de uma mesma ordem engendrada na CRFB. Enquanto a livre iniciativa denota o capitalismo existente em nossa sociedade, o qual revela o desejo de todos por lucros e acumulação de capital, a valorização do trabalho humano, ao lado da justiça social, firma a restrição dos fins estatais, consagra os direitos humanos e suaviza injustiças e opressões econômicas que ocorrem inevitavelmente nas ordens capitalistas. Isto é, podemos verificar nessa ordem o sistema de freios e contrapesos.
} 
Feita essa breve introdução, passa-se à análise dos princípios, das finalidades e dos fundamentos da ordem econômica sob o prisma das relações de trabalho.

\section{FUNDAMENTOS DA ORDEM ECONÔMICA}

3.1 Valorização do trabalho humano

A valorização do trabalho humano, princípio da ordem econômica, deve ser elevado a um axioma que norteia toda essa ordem, uma vez que é meio de garantir a existência digna (finalidade), frente às relações econômicas. $\mathrm{O}$ trabalho é necessário para o indivíduo e para toda a sociedade, independentemente da atividade exercida e da contraprestação pecuniária. $\mathrm{Na}$ realidade, com o trabalho útil e produtivo, o indivíduo se percebe como um ser humano digno e também percebe seu papel na sociedade e o sentido de sua existência.

O trabalho transcende o aspecto pecuniário em razão da percepção do indivíduo sobre si mesmo e por ser, sobretudo, um fator de produção. Numa visão neoliberal, adotada pela CRFB, o trabalho está no mesmo patamar que a natureza (recursos naturais), capital (bens de produção) e o empresário (empregador), que combina todos os fatores de produção com o ímpeto de colocá-los em atividade e produzir bens e serviços, tomando para si o risco.

Nessa pauta, existem diferentes correntes que abordam o conceito de trabalho ${ }^{102}$. Porém, além da abordagem teórica feita por economistas e filósofos, sobre trabalho (produtivo e improdutivo), necessário se faz pensar na prática e como é possível garantir esse princípio na realidade em que se vive.

Para o Poder Público, a CRFB traz a obrigação de prover a sobrevivência digna do indivíduo com o produto da remuneração de seu labor, garantindo-lhe, para tanto, uma gama de direitos sociais, como renda mínima, repouso semanal remunerado, seguro desemprego, fundo de garantia por tempo de serviço, jornada de trabalho diária e semanal máxima, gozo de férias anuais remuneradas etc.

O objetivo é primar pela proteção ao fator de produção e de mão-de-obra. Para tanto, o Poder Público deve atuar de maneira a garantir que o produto do trabalho (salário) seja capaz

\footnotetext{
${ }^{102}$ A título exemplificativo, no pensamento socialista, para Karl Marx, o trabalho só existe se for executado em prol da sociedade, não em benefício único e exclusivo do indivíduo. Já no pensamento liberal, para Adam Smith, o trabalho tem como finalidade a produção de bens num mercado tido como liberal clássico. Há uma vertente mais moderna, representada por John Stuart Mills, segundo a qual o trabalho é indispensável para a produção, mas nem sempre tem como única finalidade produção. Há muitas atividades, que mesmo muito úteis, não têm por objetivo a produção. Assim, foi feita a divisão entre trabalho produtivo e improdutivo.
} 
de lhe gerar uma renda mínima que, por si só, lhe garanta o acesso (compra) a todos os bens de consumos essenciais para se viver condignamente no seio da sociedade. Assim, tal valor deve ser o meio pelo qual o trabalhador irá efetivar todos os direitos sociais positivados no artigo $6^{\circ}$, observadas as garantias do artigo $7^{\circ}$, ambos da CRFB.

Voltando-se a uma linha de pensamento relacionada à teoria econômica, pode-se afirmar que pessoa digna é aquela que conquistou sua independência econômica, aquela que se sustenta e é capaz de gerar renda que lhe garanta acesso aos bens essenciais para uma existência digna. A valorização do trabalho humano é fator de garantia do princípio da dignidade da pessoa humana.

Ademais, a valorização do trabalho prescinde de políticas de investimento em capacitação de mão-de-obra, que deve passar por um conjunto de políticas de investimento em educação.

\subsection{Livre iniciativa}

Ao lado da valorização do trabalho humano está a livre iniciativa. Trata-se de um dos fundamentos do Estado, presente no artigo $1^{\circ}$, inciso IV, da CRFB. É expressão da liberdade dentro da ordem econômica e funciona com outros princípios constitucionais, como o da autonomia da vontade. Assim, a livre iniciativa não se faz presente apenas no campo econômico, denota ela o livre arbítrio dos indivíduos em suas escolhas diárias.

O Estado não pode obrigar um indivíduo a seguir alguma profissão, a escolha do trabalho fica ao arbítrio da liberdade do indivíduo. Nessa seara o Estado não pode interferir. Todavia, em defesa da coletividade, este deve disciplinar o exercício da livre iniciativa, impondo os requisitos mínimos necessários para o exercício da atividade laborativa, com o fito de que esta seja exercida por profissionais capacitados e habilitados. Ainda, o Estado também não pode restringir o exercício da atividade econômica, a menos que o faça para salvaguardar a sociedade e o consumidor.

Sem dúvidas, quando o Constituinte elegeu a livre iniciativa como princípio norteador da ordem constitucional, fez-se a opção por um regime de economia de mercado baseado na lei da oferta e da demanda, conferindo liberdade para os agentes econômicos.

Máxima desse regime é a "laissez-faire, laissez-passer; le monde va de lui-même” - o Estado atua como agente normativo e regulador de sua ordem econômica. Com base no princípio da subsidiariedade, a intervenção estatal somente se fará presente onde for necessária. Onde não há espaço para o Estado regular, o mercado se autorregulará. 
A interferência do Estado na livre iniciativa é lícita para assegurar a função social da propriedade, a função social da empresa, a repressão ao abuso do poder econômico, a proteção ao consumidor e a valorização do trabalho humano.

Uma vez que já fora brevemente analisada a valorização do trabalho humano, passa-se à função social da empresa. Trata-se de vetor para o exercício da atividade econômica, impondo deveres e abstenções ao Estado e à sociedade. Esse vetor, que não deixa de ser um princípio, detém função sistematizadora, ao passo que agrega aos valores caros à CRFB a ordem econômica. Pode-se verificar o cumprimento da função social da empresa será cumprido em ocasiões nas quais a empresa em si retribuir algo para a sociedade, a exemplo de criar empregos, contribuir para o desenvolvimento econômico, gerar riquezas e pagar tributos.

\section{FINALIDADES DA ORDEM ECONÔMICA}

Prevista no artigo 170, caput, da CRFB, como finalidade da ordem econômica, a existência digna denota uma qualidade de vida que permita o ser humano a satisfazer suas necessidades primárias, no mínimo. Para tanto, em razão da ordem econômica presente no Brasil, é necessário ter uma renda.

A existência digna é núcleo de proteção jurídica do princípio da dignidade da pessoa humana, sendo este uma norma fundamental da República.

Todavia, deve ser ressaltado que o Poder Público tem por histórico focar esforços em suas políticas de seguridade social, em sua vertente assistencialista, à parcela de população notadamente necessitada, isto é, ao hipossuficiente. Isto porque, em relação à parcela da população economicamente ativa, foca o Estado suas políticas na geração de empregos, de maneira a incentivar a atividade econômica e a capacidade de geração de rendas individuais, que implicará maior arrecadação de receitas.

Historicamente, o Estado tem adotado uma postura paternalista com relação à economia e aos direitos trabalhistas. Resultado disso é a concepção da Consolidação das Leis do Trabalho, advinda no Estado Novo de Getúlio Vargas, que traz vasto rol de direitos idealizados para empregados.

As normas celetistas contêm duas características marcantes: a finalidade de proteção individual do trabalhador (norma protecionista ao trabalhador) e uma forte carga de imperatividade (que, a priori, não pode ser derrogada, mesmo que por vontade do próprio 
trabalhador). Na realidade, a CLT encontrou sua inspiração na Carta do Trabalho italiana (Carta del Lavoro), com o modelo centralizado e fechado ${ }^{103}$.

No entanto, a sociedade se desenvolve, principalmente com a era globalizada e tecnológica, que potencializa a velocidade dessas mudanças e denota um ambiente mais precípuo para inovações. Com isso, não se pode mais presumir que todos os empregados são hipossuficientes, ou ainda, que o sonho de todos é ter uma carteira de trabalho assinada. Um exemplo é a nova era de empreendedorismo na internet, principalmente representada pelos novos influenciadores de mídia, que muitas vezes preferem receber bens do que um salário e ter uma carteira de trabalho assinada.

Em tempos de mudança social, principalmente num cenário de crise econômica, surgem novas formas de trabalho e deve a legislação acompanhar tais mudanças.

Foi neste contexto de intensa recessão, com um mercado de trabalho guiado por regras rígidas que impõem uma série de deveres e onera sobremaneira o empregador, que veio a Lei n. 13.467, de 13 de julho de 2017, popularmente conhecida como Reforma Trabalhista.

O Estado tem o dever de direcionar a atividade econômica para a erradicação da pobreza, acabando com as desigualdades e injustiças sociais. Para tanto, deve ele aplicar políticas que efetivem uma justa distribuição de rendas (justiça distributiva), fazendo com que as classes menos favorecidas e marginalizadas tenham acesso ao mínimo existencial em todos os setores da sociedade.

Para ser possível uma existência digna, é imprescindível o atingimento de um mínimo existencial, que não se trata apenas de um mínimo vital, mas também de um certo nível de qualidade de vida. O mínimo existencial é direito pré-constitucional e, mesmo que não positivado na CRFB, está subentendido em seu artigo $3^{\circ}$, III, como sendo um dos objetivos da República a erradicação da pobreza e da marginalização.

A fim de que todos na sociedade possam deter esse mínimo existencial, é necessário que o mercado de trabalho possa gerar empregos ou oportunidades. Para tanto, faz-se também necessária uma política legislativa no sentido de auxiliar os empregadores, como agentes econômicos, a desenvolverem suas atividades econômicas, gerar riquezas e assim gerar empregos. Com isso, também é satisfeita a busca do pleno emprego.

\footnotetext{
${ }^{103}$ A Carta del Lavoro pode ser vista como uma referência mais palpável para a CLT. Contudo, salienta-se que na primeira metade do século XX, em especial na passagem da $1^{\mathrm{a}}$ geração de Direitos Humanos para a $2^{\mathrm{a}}$ geração de Direitos Humanos, o movimento por proteção ao trabalhador era uma busca global. Outras instituições que marcaram fortemente a busca brasileira pela proteção ao trabalhador foram a Organização Internacional do Trabalho e a Igreja Católica, por meio da Encíclica Rerum Novarum, que discorre sobre as condições de trabalho dos operários.
} 


\section{PRINCÍPIOS EXPLÍCITOS E IMPLÍCITOS NA ORDEM ECONÔMICA}

No presente capítulo, serão expostos brevemente os princípios explícitos presentes na ordem econômica e ligados ao direito do trabalho.

Por meio do princípio da busca do pleno emprego, exposto no inciso VIII, busca-se a expansão das oportunidades de emprego produtivo, que tem por fim garantir que a população economicamente ativa esteja exercendo atividades geradoras de renda, tanto para si quanto para o país. Ou seja, busca-se a maximização de resultados no que tange ao uso da mão de obra, dentro dos parâmetros estabelecidos pelas normas jurídicas legisladas pelo Estado.

Quanto maior o número de pessoas trabalhando em atividades geradoras de rendas, maior será o volume de arrecadação do Poder Público, via receitas derivadas, sendo menores os gastos com o setor de seguridade social, uma vez que menos cidadãos vão ter que se valer do assistencialismo social. Assim, o Estado pode focar seus gastos em atividades promotoras de desenvolvimento tecnológico, pesquisa científica, etc.

Muitas vezes, a fim de se cumprir o objetivo da ordem econômica, a redução das desigualdades sociais regionais e sociais, o Poder Público pode interferir em setores econômicos. Um exemplo recente foi a licitude de terceirização de atividades-fim, encabeçada pelo STF.

A decisão foi proferida por maioria, nos autos do Recurso Extraordinário $\mathrm{n}^{\circ}$. 958.252/MG, o qual havia sido ajuizado antes da entrada em vigor da Reforma Trabalhista, e questionava a legalidade da Súmula $\mathrm{n}^{\mathrm{o}} 331$ do Tribunal Superior do Trabalho (TST), que proibia a terceirização de "atividades-fim", sendo este objeto recorrente de reclamações trabalhistas e ações civis públicas ajuizadas pelo Ministério Público do Trabalho.

Embora o texto da Reforma Trabalhista já fosse claro no sentido de permitir esse tipo de terceirização, o TST não havia cancelado ou alterado a Súmula $n^{\circ} 331$, situação esta que causava bastante insegurança jurídica, pela incerteza de como os tribunais interpretariam a nova lei, bem como se esta seria aplicada para casos anteriores à sua publicação.

Com essa decisão, em tese, firma-se o entendimento de que a terceirização de atividades-fim é lícita.

O princípio da busca do pleno emprego guarda estrita relação com o princípio implícito da democracia econômica. Por meio desse princípio, as políticas públicas devem ampliar a oferta de oportunidades de iniciativa e de emprego, com chances iguais para todos 
os que se encontrem na mesma situação fática e jurídica, consoante artigos $1^{\circ}, 3^{\circ}$, IV, e 170 , caput.

O princípio da democracia econômica pode ser interpretado de forma macro, para os agentes que atuam no mercado, sendo corolário da livre-iniciativa. Esse princípio também pode ser interpretado de forma micro, aplicando-o nas etapas de produção, circulação e consumo, sendo oriundo da valorização do trabalho humano, da busca do pleno emprego e da defesa do consumidor.

Nos seguintes parágrafos, não se pretende instaurar discussão sobre a política adotada no país nos últimos anos, apenas serão mostrados dados para que o leitor perceba que quanto maior a carga do governo sobre a vida da sociedade, maiores serão os indicadores negativos, como desemprego.

Nos últimos anos, ocorreu uma acentuação do engessamento dos direitos dos trabalhadores e também dos empregadores. Políticas públicas no sentido de dificultar a demissão, assim como de engessar o campo de atuação do empregador, trouxeram reflexos também na vida dos trabalhadores.

Com o decorrer do tempo, infelizmente, muitos trabalhadores passaram a ser contratados informalmente, uma vez que contratá-los passou a ser extremamente oneroso. Nesse momento, a discussão acerca da terceirização de atividades fim e atividades meio tomou corpo.

Para se ter uma ideia de como essa política pública de engessamento dos direitos do empregador afetou a todos, são trazidos dados do Fundo Mundial Internacional (FMI) ${ }^{104}$.

Em relação à taxa de desemprego, em 2010, ela se encontrava em 6,74\%; em 2011, 5,98\%; em 2012, 7,03; em 2013, 7,21\% em 2014, 6,79; em 2015, 8,31\%; em 2016, 11,26\%; 2017, 12,77\%. Em consequência, um dos principais indicadores da crise econômica, o câmbio do dólar, teve um crescimento incessante. Em 2010, o dólar equivalia a R \$ 1,69; em 2015, R\$ 3,90; em 2016, R\$ 3,26; em 2017, R\$3,31; em 2018, R\$ 3,87.

Diante do exposto, percebe-se que quanto maior o peso estatal sobre a sociedade, principalmente sobre os empregadores, menor a liberdade econômica e, em consequência, maior a taxa de desemprego, o que ocasiona invariavelmente crise econômica.

Outro princípio implícito a ser exposto é a democracia econômica.

A democracia econômica garante a participação ativa de todos na propositura de suas políticas públicas de planejamento econômico, a saber, Poder Público, agentes econômicos e

\footnotetext{
${ }^{104}$ Dados disponíveis em http://data.imf.org/?sk=4C514D48-B6BA-49ED-8AB9-52B0C1A0179B.
} 
consumidores, garantindo-se a harmonização de todos os interesses envolvidos, sem que haja preponderância de um sobre os demais.

O livre exercício da atividade econômica, princípio implícito, merece destaque. A regra é a liberdade de exercício da atividade econômica, na qual o Estado não deve interferir na manifestação volitiva de seus cidadãos para tanto. Todavia, isso não significa que o Estado, em casos de interesse público primário, não possa regular a atividade econômica, atuando com poder de polícia administrativa para fazer valer e efetivar suas medidas.

\section{REFORMA TRABALHISTA}

Como visto anteriormente, o Direito do Trabalho encontra sua origem em crise econômica, como ataque a questões sociais decorrentes do sistema econômico. Como destaca BARROS (2016, p. 63),

"o Direito do Trabalho surgiu em momento histórico de crise, como resposta política aos problemas sociais acarretados pelos dogmas do capitalismo liberal. Seu marco no contexto mundial, é o século XIX. A disciplina em estudo surgiu quando se tentou solucionar a crise social posterior à revolução Industrial. Nasceu sob o império da máquina, que, ao reduzir o esforço físico e simplificar a atenção mental, facilitou a exploração do trabalho das mulheres e dos menores, considerados "meias forças", relegando- se o trabalho do homem adulto a um plano secundário. $\mathrm{O}$ desgaste prematuro do material humano nos acidentes mecânicos do trabalho, os baixos salários e as excessivas jornadas foram, então, inevitáveis. O Direito Civil já não se encontrava apto à solução desses problemas, os quais exigiam uma legislação mais de acordo com o momento histórico-social. Isso porque a celebração e o cumprimento do contrato de trabalho disciplinados pela liberdade assegurada às partes no direito clássico, intensificavam a flagrante desigualdade dos interlocutores sociais.".

Sob o prisma político, o Estado aliou-se ao proletariado que surgia com o deslocamento do poder das oligarquias rurais para as classes médias urbanas. Em favor desse proletariado editou-se uma legislação generosa para a época, com a remuneração de que sua proteção deveria vir do Estado, não dos sindicatos, que eram hostilizados porque não podiam ser controlados pelo poder público. Por outro lado, o Estado ofereceu proteção laboral paralelamente à proteção econômica concedida ao empregador.

Com as diversas crises do capitalismo, bem ensina NASCIMENTO (2014, p. 74) que

"A conjuntura internacional mostra uma sociedade exposta a sérios problemas que atingiram em escala mundial os sistemas econômicos 
capitalistas. Os empregos diminuíram, cresceram outras formas de trabalho sem vínculo de emprego, as empresas passaram a produzir mais com pouca mão de obra, a informática e a robótica trouxeram produtividade crescente e trabalho decrescente".

Essas mudanças desencadearam a discussão sobre a flexibilização do emprego. Ainda, o Estado do Bem-Estar Social que vigorou durante grande parte do século XX e que tinha uma concepção mais solidária de proteção ao ser humano como empregado começou a entrar em crise nos anos 60. Como consequência desse fenômeno no Brasil, a estabilidade no emprego começou a ser substituída pelo FGTS.

A década de 90 refletiu uma política neoliberal, como a mitigação do conceito de Estado do bem-estar social. Enquanto se privilegiavam os grandes grupos econômicos, as pequenas e medias empresas quebraram em decorrência do dano causado pelas políticas econômicas. A saúde, a educação, a segurança e a previdência foram relegadas a um plano secundário.

Nesse contexto de recessão e de um Estado paternalista com intervenção extrema na economia, a polêmica Reforma Trabalhista, introduzida pela Lei n. 13.467/2017, trouxe inúmeras alterações à CLT. Dentre elas, alterou o critério utilizado para deferimento de justiça gratuita, determinou a cobrança de honorários advocatícios e periciais em caso de sucumbência, estabeleceu teto às custas e determinou a cobrança de custas judiciais àqueles que derem causa ao arquivamento de ações devido ao não comparecimento injustificado à audiência. A Reforma também trouxe previsão legal para novas formas de trabalho, como o teletrabalho, a terceirização e o trabalho intermitente, e determinou que os termos negociados prevaleçam sobre o legislado.

Trata-se de verdadeiro desincentivo às aventuras jurídicas, tanto é que com um ano da entrada em vigor da reforma trabalhista, pode-se vislumbrar uma moralização das reclamações trabalhistas, seja pelo temor relativo ao pagamento de custas e honorários, seja pela insegurança em relação à ausência de sedimentação jurisprudencial de algumas matérias.

Tais mudanças são importantes para se resgatar o senso de responsabilidade em ingressar na máquina judiciária, assim como trazem confiança ao Poder Público. Antes da Reforma, como havia o ajuizamento massivo e inconsequente de reclamações trabalhistas, a Justiça acabava por ser morosa. Tanto é que, no ano de 1998, em indagação realizada pela Grottera Pesquisas em São Paulo, às classes A, B, C, D e E (Grottera, 1998), já se evidenciava o desconhecimento do Poder Judiciário, por alguns, e o descontentamento pela morosidade e formalismo, por parte de outros. Respondendo à pergunta "quem mais ajuda a fazer justiça 
para a maioria dos brasileiros?" $84 \%$ dos entrevistados indicaram a mídia, restando ao Judiciário $10 \%$, às Associações 4\%, e ao Governo, $2 \%$ das indicações ${ }^{105}$.

O cenário político do país, além de trazer instabilidade econômica, reflete também nas decisões do poder judiciário com total ausência de uniformidade, gerando enorme insegurança jurídica, e por consequência, insatisfação social.

Tanto é que a recém editada Lei n. 13.467/2017 já foi alvo de inúmeras ações diretas de inconstitucionalidade, são exemplos: ADI 5766, ADI 5794, ADI 5806, ADI 5810, ADI 5811, ADI 5813, ADI 5815, ADI 5826, ADI 5829, ADI 5850, ADI 5859, ADI.5865, ADI 5867, ADI 5870, ADI 5885, ADI5887, ADI 5888, ADI 5892, ADI 5900, ADI 5912, ADI 5913 e ADI 5923.

Tais ações questionam diversos temas, como a obrigatoriedade do pagamento de custas, mesmo se beneficiário da justiça gratuita, o fim da obrigatoriedade no pagamento da contribuição sindical.

O grande desafio do Poder Judiciário é a busca pela segurança jurídica, uma vez que se vive uma cultura de descrédito, em que há a necessidade de se aguardar o trânsito em julgado de uma decisão do STF.

\subsection{A flexibilização da legislação trabalhista}

O Direito do Trabalho, assim como o Direito de modo geral, surge na sociedade justamente com o intuito de regular a vida social e garantir a segurança na organização social.

Com a internacionalização da economia, a concepção de Estado burocrático não é mais viável, sendo imprescindível a modernização das normas jurídicas de forma a abarcar as novas relações entre o trabalhador e as empresas.

Nesse modelo de globalização, o Direito deverá ser capaz de regular situações mesmo que não as tenha previsto e, para tanto, cada vez mais as formas rígidas de controle pensadas para a relação comum de empregado e empregador serão um impasse para a livre iniciativa e a liberdade de trabalho.

Algumas alterações trazidas pela legislação, tais como a prevalência dos termos negociados sobre o legislado e as novas formas de contratação, analisadas conjuntamente, possuem a tendência de flexibilizar o mercado de trabalho brasileiro, por meio da redução da rigidez normativa trabalhista.

\footnotetext{
105 GROTTERA, Luís. O Judiciário ausente na mídia é um risco para a democracia. Revista Cidadania e Justiça, ano $2, \mathrm{n}^{\circ} 5$ - $2^{\circ}$ sem., 1998, p.114 - 126.
} 
Economicamente, convém ressaltar, que alguma rigidez se faz necessária, vez que aumenta a previsibilidade e traz uma segurança jurídica. No entanto, não pode a legislação ser engessada de tal forma a ponto de afetar a eficiência do mercado de trabalho e reduzir o bemestar dos indivíduos.

A valorização da negociação coletiva, trazida pela Reforma Trabalhista, é uma tendência mundial e extremamente necessária quando se trata de um país com dimensões continentais como o Brasil. Não há como uma mesma legislação refletir a realidade do interior da região norte e da região central de São Paulo ao mesmo tempo.

A negociação coletiva possibilita que as diferentes realidades econômicas e sociais sejam observadas e disciplinadas de forma específica, trazendo maior segurança jurídica às partes e alavancando a economia.

Assim como o privilégio à negociação coletiva reflete a tendência atual à flexibilização, as novas formas de contrato de trabalho trazidas pela novel legislação trilha o mesmo rumo.

A doutrina trabalhista classicamente divide as diversas modalidades de contrato de trabalho observando a duração (prazo determinado ou indeterminado), o tipo de trabalho (manual, intelectual ou técnico), a finalidade (industrial, comercial, agrícola, doméstico ou marítimo), os sujeitos da relação (individual ou coletivo), o lugar do trabalho (em domicílio, a distância ou em local designado pelo empregador) a forma de remuneração (salário fixo ou variável), a forma (verbal ou por escrito), e, por fim, a manifestação de vontade (tácita ou expressa).

Via de regra os contratos de trabalho dão-se por prazo indeterminado. No entanto, há previsão no texto consolidado para contratos por prazo determinado, exceção que deveria corresponder aos ditames legalmente autorizados. São algumas espécies de contrato por prazo determinado: por obra certa, de safra, de experiência, a prazo certo, de técnico estrangeiro, de atleta profissional, de artistas e de aprendizagem.

Conforme dito anteriormente, com a Lei n. 13.467/17 foram criados novos modelos de contrato de trabalho, como o de teletrabalho ou home office, o de trabalho intermitente, o de profissional autônomo exclusivo e o contrato de trabalho sob a jornada 12 x 36 horas.

O teletrabalho, previsto nos artigos 75-A a 75-E da nova Lei, trata-se de prestação de serviços preponderantemente fora das dependências do empregador, com a utilização de tecnologias de informação e de comunicação que não se constituam como trabalho externo. Necessária previsão expressa no contrato individual de trabalho com a descriminação das 
atividades. Essa modalidade de contratação está fora do controle de jornada por expressa previsão legal.

O contrato de trabalho intermitente, é instituto completamente novo trazido pela Reforma Trabalhista, não tinha previsão legal na redação original da CLT, vindo previsto no artigo 452-A. Trata-se de uma das mais polêmicas figuras trazidas. Há previsão de que deve este contrato se celebrado por escrito, contendo especificamente o valor da hora de trabalho, que não pode ser inferior ao valor horário do salário mínimo ou àquele devido aos demais empregados do estabelecimento que exerçam a mesma função em contrato intermitente ou não. Trata-se de prestação de serviços, com subordinação, não contínua, ocorrendo com alternância de períodos de prestação de serviços e de inatividade. O período de inatividade não será considerado tempo à disposição do empregador, podendo o trabalhador prestar serviços a outros contratantes. Ademais, a oferta do trabalho deve ser apresentada pelo empregador ao menos três dias antes do início do contrato. Já o empregado terá um dia útil para responder se aceita ou não a proposta.

O profissional autônomo exclusivo também foi uma das novidades questionadas, por ser a forma de trabalho com mais semelhanças com a relação típica de emprego.

$\mathrm{O}$ artigo $3^{\circ}$ da CLT (que não foi alterado pela Reforma) define como requisitos para um profissional ser considerado empregado: a habitualidade, subordinação e salário. Embora não esteja elencada entre os requisitos, a "exclusividade" do profissional também era uma das evidências aceitas pela Justiça como comprovação do vínculo empregatício.

Com a Reforma, as empresas podem contratar autônomos e, ainda que haja relação de exclusividade e continuidade, não precisará ocorrer a assinatura da Carteira de Trabalho, ficando assim os trabalhadores desassistidos dos direitos previstos no artigo $7^{\circ}$ da CRFB.

Agora o elemento "exclusividade" perderá força na hora da comprovação do vínculo empregatício judicialmente, de forma que outros critérios deverão ser usados, como a subordinação.

Com a legalização da jornada de 12 por 36 horas, que na redação original da CLT só seria possível mediante convenção coletiva, com base no que dispõe o artigo 59-A, passou a ser facultado às partes, mediante acordo individual escrito, convenção coletiva ou acordo coletivo de trabalho, estabelecer horário de trabalho de doze horas seguidas por trinta e seis horas ininterruptas de descanso, observados ou indenizados os intervalos para repouso e alimentação. A remuneração mensal pactuada pelo horário previsto abrange os pagamentos devidos pelo descanso semanal remunerado e pelo descanso em feriados, e serão considerados compensados os feriados e as prorrogações de trabalho noturno. 
Importante se ressaltar que em quaisquer dessas hipóteses a fraude ou qualquer outra nulidade na contratação, será punida e, uma vez verificados os requisitos da qualidade de empregado, deverá ser declarado o vínculo.

Um dos objetivos da Reforma Trabalhista com tais inovações foi o de diminuir a informalidade no mercado de trabalho, permitindo que os prestadores de serviços antes não regulados pela CLT, passem a ter acesso aos direitos trabalhistas e previdenciários.

\section{7 ÍNDICES DE DESEMPREGO}

Como já se explicitou anteriormente, ocorreu um engessamento dos direitos dos trabalhadores e dos empregadores. Um exemplo do engessamento foi a dificuldade de demissão, o que reflete de forma negativa aos empregadores imediatamente, mas também de forma negativa aos trabalhadores a longo prazo.

Com tais políticas, mais trabalhadores passaram a ser contratados informalmente, uma vez que a contratação se tornou muito onerosa. Como resultado, veio a Reforma Trabalhista com o fito de diminuir a informalidade, flexibilizar contratações e demissões e, consequentemente, tentar reduzir o desemprego.

Como já exposto pelos dados do Fundo Monetário Internacional, ao passo que a legislação trabalhista se tornou mais rígida, o nível de desemprego subiu. Quanto maior o peso estatal sobre a sociedade, principalmente sobre os empregadores, menor a liberdade econômica e, em consequência, maior a taxa de desemprego.

Em relação a indicadores mais recentes sobre desemprego, o Instituto Brasileiro de Geografia e Estatística (IBGE) lançou informações desanimadoras sobre o desemprego no começo de 2019.

Entre março e maio de 2017, pouco antes da promulgação da Reforma Trabalhista, o desemprego estava em 13,3\%. Entre junho e agosto, na aprovação e promulgação da Reforma, o desemprego caiu para 12,6\%, talvez como resposta imediata do mercado. Mas, entre setembro e novembro de 2017 , caiu para $12 \%$, o que mostrou um reflexo positivo da Reforma.

Houve um aumento do desemprego nos meses seguintes, chegando a 12,7\% o nível de desemprego em maio de 2018. Nos próximos meses, ocorreu uma queda do desemprego, estando o nível a $11,6 \%$. 
Recentemente, o IBGE divulgou pesquisa segundo a qual o desemprego aumentou e está em $12,4 \%{ }^{106}$.

Diante dos dados, percebe-se que houve uma redução imediata do desemprego. No entanto, infelizmente, houve um aumento do desemprego desde a posse do presidente Jair Bolsonaro - passou de $11,6 \%$ para $12,4 \%$. De qualquer maneira, o índice caiu aproximadamente $1 \%$ desde a promulgação da Reforma Trabalhista.

\section{CONSIDERAÇÕES FINAIS}

Acredita-se que o tempo de avaliação é expressivo, mas não o suficiente para julgar a Reforma Trabalhista como um retrocesso ou um progresso. Nesse interregno, ocorreram as eleições presidenciais e estaduais, que chacoalharam fortemente a economia.

Vargas trouxe um elemento na CLT de 1943 que cresceu exponencialmente, de modo que a liberdade econômica dos empregadores foi mitigada e suas mãos foram atadas em diversos sentidos. Esse elemento foi o gérmen da hipossuficiência do empregado frente ao empregador, que teve suas raízes aprofundadas com a Justiça Trabalhista.

Apesar de a novel legislação não reduzir o desemprego como antes esperado, é importante pensar também em outros índices, como o de número de processos ajuizados na Justiça Trabalhista. Entre janeiro e setembro de 2017, foram ajuizados 2.013.241 processos. Nesse mesmo período em 2018, o número de processos ajuizados caiu para 1.287.208 ${ }^{107}$.

Antes da Reforma Trabalhista, havia uma verdadeira indústria de reclamações trabalhistas indevidas, que expressavam o caráter beligerante e de má-fé de muitos empregados contra seus empregadores. Essa indústria cresceu tanto que o número de ações trabalhistas no Brasil passou a representar $98 \%$ das ações trabalhistas mundiais, mesmo detendo apenas $2 \%$ da população mundial ${ }^{108}$.

\footnotetext{
106 BRASIL, Instituto Brasileiro de Geografia e Estatística. Desemprego sobe para 12,4\% e população subutilizada é a maior desde 2012. Disponível em https://agenciadenoticias.ibge.gov.br/agencia-noticias/2012agencia-de-noticias/noticias/24110-desemprego-sobe-para-12-4-e-populacao-subutilizada-e-a-maior-desde-2012. Acesso em: 27 abr. 2019.

${ }^{107}$ BRASIL, Tribunal Superior do Trabalho. Primeiro ano de Reforma Trabalhista: efeitos. Disponível em http://www.tst.jus.br/noticias/-/asset_publisher/89Dk/content/primeiro-ano-da-reforma-trabalhistaefeitos/pop_up?_101_INSTANCE_89Dk_viewMode=print\&_101_INSTANCE_89Dk_languageId=pt_BR. Acesso em: 26 abr. 2019.

108 CONJUR. Excesso de proteção ao trabalhador é um problema, diz Barroso. Disponível em https://www.conjur.com.br/2017-mai-19/excesso-protecao-trabalhador-problema-barroso. Acesso em: 27 abr. 2019.
} 
Com a Reforma, os litigantes de má-fé são condenados em até 10\% do valor da ação. Além disso, deverão ser feitos pedidos líquidos e certos e os honorários de sucumbência serão aplicados.

Muitos empregadores eram afetados por essa indústria de reclamações a ponto de não poderem mais continuar suas atividades empresariais. Assim como as reclamações, os rearranjos societários e trabalhistas, muitas vezes imprescindíveis, causavam grande impacto na saúde financeira das empresas, pois as verbas rescisórias devidas aos trabalhadores eram exorbitantes.

Mesmo que exista uma dificuldade de recolocação dos trabalhadores no mercado, são as empresas que garantem essa reposição. Se as empresas tiverem a saúde financeira tão afetada a ponto de precisarem fechar suas portas, como se via nos últimos anos, a recolocação no mercado de trabalho nunca será satisfatória.

Para tanto, a Lei n. 13.467/2017 vem com o fito de desonerar os empregadores a fim de que eles possam continuar suas atividades e possam empregar mais, recompondo o mercado de trabalho. Assim a livre iniciativa deixa de ser mitigada e passa a ser respeitada como a fonte de empregos que sempre foi.

Além dessa finalidade, tal lei também apresenta meios de regular novos meios de trabalho que tendem a se expandir, como o home office.

Mesmo que a taxa de desemprego não tenha cessado tanto como o esperado, inúmeros são os ganhos com a Reforma - regulação de novos meios de trabalho, derrocada da indústria das reclamações trabalhistas, maior espaço de atuação para entidades de classe, maior relevância para o negociado, etc.

Acredita-se que a Reforma Trabalhista não afetará mais a informalidade, uma vez que, com a crise econômica instalada no Brasil nos últimos anos, milhões eram os empregados contratados sem qualquer registro, sem ter a carteira de trabalho assinada, sem ter acesso a seus direitos trabalhistas constitucionais. Com a Reforma, muitos desses trabalhadores terão a chance de revisitar seus contratos de trabalho, podendo demandar e usufruir de seus direitos trabalhistas. Nesse sentido, é evidente que a valorização do trabalho humano não foi afetada de forma negativa.

Além do respeito aos fundamentos da ordem econômica, quiçá a Reforma Trabalhista garantirá objetivos da ordem econômica, como a redução das desigualdades e injustiças sociais e a erradicação da pobreza, ao passo que poderá reaquecer o mercado de trabalho.

Em relação aos princípios implícitos da ordem econômica, com a nova lei, a busca pelo pleno emprego será reativada, uma vez que o desemprego tende a cair, mesmo que em 
marcha lenta. Ainda, como os custos trabalhistas serão reduzidos, haverá maior margem de manobra financeira do empresariado e, consequentemente, uma realocação mais eficiente do capital dos empregadores, o que permitirá uma ampliação da democracia econômica. Num momento posterior, com o desemprego reduzido, a democracia econômica também estará a alcance dos empregados, ao passo que eles terão recursos excessivos para alocarem da maneira que quiserem.

A Reforma Trabalhista ainda não trouxe os resultados que todos esperavam e que precisam inclusive, no tocante ao desemprego. Contudo, diversos são os ganhos, como se expôs anteriormente. Com esses ganhos, a economia acaba por ser reaquecida paulatinamente. Isto é, a redução da taxa de desemprego é uma questão de tempo e que, na opinião das autoras do presente artigo, não demorará para reverberar.

\section{REFERÊNCIAS}

Democracia, constituição e princípios constitucionais: notas de reflexão do Direito Constitucional Brasileiro. Revista de Direito da Universidade Federal do Paraná. Disponível em <http://egov.ufsc.br/portal/sites/default/files/anexos/15770-15771-1-PB.pdf >. Acesso em: 01 nov. 2018.

Estado e livre-iniciativa na experiência constitucional brasileira. Revista Brasileira de Direito Público: RBDP, Belo Horizonte, v. 12, n. 45, p. 9-19, abr.jun. 2014. Disponível em https://bdjur.stj.jus.br/jspui/handle/2011/81024.

população subutilizada é a maior desde 2012. Disponível em https://agenciadenoticias.ibge.gov.br/agencia-noticias/2012-agencia-denoticias/noticias/24110-desemprego-sobe-para-12-4-e-populacao-subutilizada-e-a-maiordesde-2012. Acesso em: 27 abr. 2019.

Lei 6.931, de 31 de agosto de 1981.

Tribunal Superior do Trabalho. Primeiro ano de Reforma Trabalhista: efeitos. Disponível em http://www.tst.jus.br/noticias/-/asset_publisher/89Dk/content/primeiro-ano-dareforma-trabalhista-

efeitos/pop_up?_101_INSTANCE_89Dk_viewMode=print\&_101_INSTANCE_89Dk_langu ageId=pt_BR. Acesso em: 26 abr. 2019. 
BARROSO, Luís Roberto. Curso de direito constitucional contemporâneo: os conceitos fundamentais e a construções do novo modelo. $5^{\text {a }}$ ed. São Paulo: Saraiva, 2015.

BARZOTTO, Luis Fernando. Justiça Social - Gênese, estrutura e aplicação de um conceito. Revista Jurídica Virtual Brasília, v. 5, n. 48, maio 2003. Disponível em https://revistajuridica.presidencia.gov.br/index.php/saj/article/view/747/738. Acesso em 07 nov. 2018.

BONAVIDES, Paulo. Curso de Direito Constitucional. 15 ed. Malheiros: 2004.]

BRASIL. Constituição da República Federativa do Brasil de 1988.

CANOTILHO, José Joaquim Gomes. Direito Constitucional e Teoria da Constituição. 4. ed. Coimbra: Almedina, 1997.

CONJUR. Excesso de proteção ao trabalhador é um problema, diz Barroso. Disponível em https://www.conjur.com.br/2017-mai-19/excesso-protecao-trabalhador-problema-barroso. Acesso em: 27 abr. 2019.

DE BARROS, Alice Monteiro. Curso de direito do trabalho. 10 a ed. São Paulo: LTr, 2016.

ESPÍNDOLA, Ruy Samuel. Conceito de princípios constitucionais: sua revisão no discurso de juristas brasileiros, a partir da contribuição de J. J. Gomes Canotilho. Dissertação de Mestrado apresentada no Centro de Ciências Jurídicas da Universidade Federal de Santa Catarina, em $1996 . \quad$ Disponível em http://repositorio.ufsc.br/xmlui/handle/123456789/76484. Acesso em: 04 nov. 2018.

FIGUEIREDO, Leonardo Vizeu. Lições de direito econômico. $9^{\text {a }}$ ed. rev. e ampl. Rio de Janeiro: Forense, 2016.

\section{$\bullet$}

GAZETA DO POVO. Por que o Brasil despencou no ranking de liberdade econômica?, por Rodrigo Constantino. Disponível em <https://www.gazetadopovo.com.br/rodrigoconstantino/artigos/por-que-o-brasil-despencou-no-ranking-de-liberdade-economica/> .

Acesso em: 27 set. 2018.

GRAU, Eros Roberto. A Ordem Econômica na Constituição de 1988. 11 $1^{\text {a }}$ ed. São Paulo: Malheiros, 2006. p. 215. 
GROTTERA, Luís. O Judiciário ausente na mídia é um risco para a democracia. Revista Cidadania e Justiça, ano 2, n 5 - 2ºm., 1998, p.114 - 126.

INTERNATION MONETARY FUND. International Financial Statistics. Disponível em http://data.imf.org/?sk=4C514D48-B6BA-49ED-8AB9-52B0C1A0179B. Acesso em: 12 abr. 2019.

LAMY FILHO, Alfredo. A função social da empresa e o imperativo de sua reumanização. Revista de Direito Administrativo, Rio de Janeiro, v. 190, p. 54-60, out. 1992. ISSN 2238$5177 . \quad$ Disponível em: <http://bibliotecadigital.fgv.br/ojs/index.php/rda/article/view/45408/47594>. Acesso em 07 nov. 2018.

MIRANDA, Jorge. A dignidade da pessoa humana e a unidade valorativa do sistema de direitos fundamentais. In: Tratado Luso-Brasileiro da dignidade humana. Coordenação: Jorge Miranda e Marco Antônio Marques da Silva. São Paulo: Quartier Latin, 2008, p. 167176.

NASCIMENTO, Amauri Mascaro. Curso de direito do trabalho. 29a ed. São Paulo: Saraiva, 2014.

ROTHERbURG, Walter Claudius. Princípios Constitucionais. Revista da Faculdade de Direito da UFPR, Curitiba, ano 29, n. 29, 1996, p. 199-238. Disponível em https://revistas.ufpr.br/direito/article/view/9393. Acesso em 07 nov. 2018.

DA SILVA, José Afonso. Curso de direito constitucional positivo. 23․ ed. São Paulo: Malheiros, 2004.

DA SILVA, Virgílio Afonso. O conteúdo essencial dos direitos fundamentais e a eficácia das normas constitucionais. Revista de Direito do Estado, 2006. p. 23 - 51.

TAVARES, André Ramos. Curso de Direito Constitucional. 10 ${ }^{\mathrm{a}}$ ed. rev. e atual. São Paulo: Saraiva, 2012.

VATICANO. Carta Encíclica 'Rerum Novarum' do sumo pontífice Papa Leão XIII a todos os nossos veneráveis irmãos, os patriarcas, primazes, arcebispos e bispos do orbe católico, em graça e comunhão com a sé apostólica sobre a condição dos operários. Disponível em http://w2.vatican.va/content/leo-xiii/pt/encyclicals/documents/hf_lxiii_enc_15051891_rerum-novarum.html. Acesso em: 26 abr. 2019. 
WANG, Daniel Wei Liang. Escassez de recursos, custos dos direitos e reserva do possível na jurisprudência do STF. In: SARLET, Ingo Wolfgand; e TIMM organizadores, 2008, p. 350.

\title{
ECONOMIC ORDER AND THE LABOR REFORM
}

\begin{abstract}
The Brazilian constitutional economic order is grounded in the valuation of human work and in the free enterprise, values that can frequently collide in a neoliberal market system. With the enactment of the Labor Reform, a lot is said about the devaluation of human work and the mitigation of dignity of human beings. In this sense, the foundations, the principles and the goals of the economic order will be analyzed, therefore it is possible to understand if the Labor Reform indeed damaged the worker's conditions or if it is able to revive the economy and reduce the unemployment rate.
\end{abstract}

Keywords: Economic Order. Economy. Labor Reform. Unemployment. 